\title{
A FRAMEWORK OF PROJECT CULTURE IN ORGANIZATIONS
}

\author{
Ganesh Vaidyanathan, Indiana UniversitySouth Bend, gvaidyan@iusb.edu
}

\begin{abstract}
The impacts of organizational factors have been a topic of ongoing research in project management. There is ample evidence in the current literature that the institution of project culture in organizations has positive effects on how projects are implemented using project management principles. Project culture has been recognized as a contributing factor for organizational project outcomes and successes. Organizations should assess their project culture and their cultural orientation and make significant efforts to make project culture very visible and a measurable factor. This study focuses on identifying the key elements of project culture in organizations. The identified factors are then considered to formulate five dimensions of culture. A framework consisting of those five dimensions is presented.
\end{abstract}

Keywords: Project culture, Project Management, Organizational Culture, Framework, Dimensions of Culture

\section{INTRODUCTION}

Strategic initiatives are often implemented as projects to improve the performance of an organization. One of the important but lesser known factors of successful implementation of projects in organizations is its existing project culture. A study conducted by the Project Management Institute (PMI) reported that the value of project management is dependent on organizational culture when implementing projects (Thomas \& Mullaly, 2009). To enhance success in their projects, organizations need to develop a project-centered culture (Christenson \& Walker, 2004). Shore (2008) provided substantial insight into organizational and project cultures of failed projects. He suggested that failed projects are related to organizational and project cultures. Just after the Columbia Shuttle disaster on February 1, 2003, many concluded that technology was to blame for the incident. But, the Columbia Accident Investigation Board concluded that NASA had created a project culture where people were unwilling to speak up and in which systematic biases — predispositions common to human decision-making process - went unchecked (Shore, 2008).

Projects are identified, planned, and implemented in different social, cultural, economic, technological, legal, global, and political environments. Project managers need to adjust to such organizational environments surrounding their projects in order to bring the projects to fruition. Project culture is essential to create an environment that is conducive to all project stakeholders and not hinder project managers to identify both intended and unintended positive and/or negative impacts and make adjustments. For example, a well-known national construction company secured the first major water retention barrage construction project in an area in India known for its local labor problems. After understanding the political and cultural problems, the project leadership consulted with local elders and subcontracted locals for employment even though by law the company must employ its own men first. The company built all necessary facilities needed by its employees and their families including schools, hospitals, stores, clubs, and restaurants. The project was completed on schedule and to the satisfaction of all stakeholders as the project leadership understood the significance of managing the project environment. The national construction company had placed a culture where project managers can work well with the locals in order to implement the project successfully (Wideman, 1990). Organizations look up to their leadership teams to introduce and maintain a culture that helps projects to run smoothly and be successful. The processes that organizations implements and the values it communicates determine their culture (Schneider et al., 1996). How is this different than project culture? What factors are influenced by project culture? What are the dimensions of project culture? How are those dimensions related to project management activities? 
The objective of this paper is to identify key dimensions of project culture that can display a positive impact on project success. Using those dimensions, we will develop a framework of project culture that may be used by organizations when they initiate, plan, and implement projects to enhance their strategic initiatives. The structure of this paper is as follows. In the next section, we discuss the details of how culture plays an important role in successful implementation of projects. In the following section, we identify the dimensions of project culture and develop a framework of culture that can be used by managers when they plan and implement their projects. The last section includes the conclusion and future research.

\section{PROJECT CULTURE}

Project culture plays a vital role in the winning strategy required for successful implementation of a project. Organizational culture is a pattern of assumptions that are general in nature developed as an organization learns to cope with its environment (Schein, 2004) or as Silvester et al. (1999) said, "the way things are done around here". Culture is based on three categories of belief including beliefs about how employees are treated and the opportunities presented to them, beliefs about professionalism and support of efforts to do a good job, and beliefs about how an organization interferes with its environment to accomplish its mission (Chell, 1994). There are four types of culture including a control culture which revolve round power, a collaboration culture that encompasses teamwork, a competence culture that endorses achievement, and a cultivation culture that addresses growth and potential (Schneider, 1994).

Project culture is derived from organizational culture. While organizational culture is developed by senior management, project culture can be established by senior management, project management office (PMO), and project teams. Project culture impacts project processes and relationships between team members. It builds on the attitudes and behaviors of project team members (Zuo \& Zillante, 2006). Project culture is a complex set of ideologies and core values that are experienced by the members of a project team and which influences how projects are managed. According to the Project Management Body of Knowledge (PMBOK ${ }^{\circledR}$ ) guide (2008), the factors of such values include overall tone of the shared employee experience, shared visions, mission statements, expectations, motivation, rewards, views on leadership, authority relationships, work ethic, codes of conduct, environmental factors, social norms, and risk tolerance. In the next section, factors such as above will be reviewed, supported by current literature, and classified as five broad dimensions of project culture.

\section{PROJECT CULTURE DIMENSIONS}

Project culture impacts the philosophical, implementation, and management practices of projects. Positive culture inspires implementation of projects successfully. Organizations with a prominent project culture tend to provide the project manager with significant authority over the project team or make available dedicated project teams to complete critical projects. While senior leadership forms the culture of the organization, project leadership builds project culture (Müller \& Turner, 2006). Project culture results from project management principles projected by the project leader while encouraged by organizational culture. Project culture in turn defines initiation, planning, executing, controlling, and closing of projects.

Project culture has been examined by researchers in many ways. Xiaoli and Hongping (2011) divided project culture into four levels that includes substance culture, conduct culture, system culture and spirit culture. Substance culture includes products generated by project team members and facilities. Conduct culture includes the behavior of team members. System culture includes systems related to human resources and communication management. Spirit culture forms a bond between team members for teamwork. Ankrah et al. (2009) related his research to workforce orientation, performance orientation, team orientation, client orientation, and project orientation.

Prior research looks at project culture as a consequence of organizational culture in various ways. Dube and Robey (1999) listed cultural themes in software organizations as humanist image, pride, survival instinct, cultural differences with outsourcing partner, uncertainty, constant changes, challenging work, difficulties in working together, and resistance to change. They found that the three different culture perspectives including integration, differentiation, and fragmentation perspectives are related to those cultural themes and various practices of organizations. Cameron and Quinn (1999) developed a theoretical model using the major indicators of effective organizations and organized those indicators into four main clusters that included as clan, adhocracy, hierarchy and market. The clan culture emphasizes participation, cohesion, shared values, commitment and high morale. The 
adhocracy culture adopts innovation and initiatives and encourages entrepreneurial, creative and visionary behavior. The hierarchical culture relies on in a structured workplace with formal rules and policies and a focus on efficiency, timeliness, and control. The market culture believes in results and production oriented organization. Their study used an instrument consisting of six constructs including dominant characteristics of an organization, organizational leadership style, management of employees, organization bonding mechanisms, strategic emphases, and criteria of success.

The selection of a competent project team is important to project success. The selection of a project manager and a team tend to depend upon organizational culture, i.e., based on how organizations perceive the value of project management. Such a project team can project positive team potency. Project team potency is influenced by project team culture and the project success is influenced by project team potency (Nair et al., 2012). Team potency is defined as shared confidence in a team's general capabilities. Doolen et al. (2003) illustrated those relationships between team leader effectiveness, team satisfaction, and organizational culture leads to better communication and team cooperation. How knowledge is transferred and encouraged in organizations depends on culture transfer processes. A project orientation in fact may restrain knowledge transfer as it leads to knowledge silos (Eskerod \& Skriver, 2007). Organizational management should promote equitable treatment of their employees by providing them with proper authority. Authority, responsibility, accountability, and reliability are the fundamental foundations of organizational structure (Vaidyanathan, 2013). From the above mentioned literature, a number of impact factors of project culture can be derived. Table 1 summarizes those factors as five dimensions of project culture.

Table 1. Impact Factors of Project Dimensions

\begin{tabular}{|c|c|}
\hline Project Culture Dimensions & Impact Factors of Project Culture \\
\hline $\begin{array}{l}\text { Process } \\
\text { (How we work!) }\end{array}$ & $\begin{array}{l}\text { Continuously Improved, integrated, and mature processes } \\
\text { Well-established budgeting process } \\
\text { Well-established change management process } \\
\text { Well-established communication protocols to all stakeholders } \\
\text { Well-established knowledge management process } \\
\text { Well-established procurement audit process } \\
\text { Well-established project selection process } \\
\text { Well-established risk management process } \\
\text { Well-established roles and responsibilities }\end{array}$ \\
\hline $\begin{array}{l}\text { Resources } \\
\text { (What we have!) }\end{array}$ & $\begin{array}{l}\text { Availability and accessibility to prior project knowledge } \\
\text { Availability and accessibility to process assets } \\
\text { Availability and accessibility to project management software } \\
\text { Availability and accessibility to project management tools }\end{array}$ \\
\hline $\begin{array}{l}\text { Environment } \\
\text { (What we work with!) }\end{array}$ & $\begin{array}{l}\text { Alignment of official and operational rules } \\
\text { Alignment with company vision } \\
\text { Conducive to making improving changes in work processes } \\
\text { Flexibility for innovation to lower costs and shorten schedules } \\
\text { Learning-centered and transfer of knowledge } \\
\text { Mature project management structure } \\
\text { Nonpolitical and conflict-free } \\
\text { Open communication policy } \\
\text { Project manager empowerment } \\
\text { Recognition- and Rewards-oriented } \\
\text { Selection of value-added projects } \\
\text { Supportive and committed top management } \\
\text { Training facilities }\end{array}$ \\
\hline
\end{tabular}




\begin{tabular}{|l|l|}
\hline Management & Promotion of work ethic, social norms, and codes of conduct \\
\hline & Adequate project planning \\
& Competent and committed project manager selection \\
& Competent, confident, and committed team selection \\
& Selection of responsible, accountable, and reliable project team \\
& Customer-centered project implementation \\
& Proper closure after completion \\
& Proper authority bestowed on project managers \\
& Well-established monitoring and controls \\
& Well-established contracts management \\
& Well-established project closure communication \\
& Well-established quality management \\
& Well-established communication of priority and status \\
\hline Project Characteristics & Flexibility towards and awareness of project scale and size \\
(What type of projects?) & Flexibility towards and awareness of project complexity \\
\hline
\end{tabular}

\section{PROJECT CULTURE FRAMEWORK}

In this section, each one of the five project culture dimensions are defined and described. A framework of project culture is also formulated. The five dimensions of project culture from Table 1 are cultures resulting from project process, project resources, project environment, project management, and project characteristics.

\section{Project Process}

A project process is a specific ordering of structured activities and a continued improvement of such processes are vital to project outcomes that meet stakeholder requirements. Project process have to be mature, i.e., capable of delivering successful projects over time. Organizations should enable their processes to be capable of being applied to all their projects (Vaidyanathan, 2013). A properly implemented organizing process should result in a work environment where all team members are aware of their responsibilities. Budgetary process needs to be well established with distributional fairness. Social norms including honesty, distributional fairness, and reciprocity may affect budgetary slack (Douthit \& Stevens, 2015). Similarly, change management, communication protocols to all stakeholders, knowledge management, procurement audit, project selection, and risk management processes should be well established and encouraged by management to be followed in their organizations. If processes are not formulated and implemented well, it may lead to confusion, frustration, loss of efficiency, and limited effectiveness. A mixture of appropriate processes and culture facilitates organizations to learn from past experiences and avoid reinventing the wheel (Williams, 2007).

\section{Project Management}

Project management is the act of collaborating with people and using other resources in an organization to bring projects to fruition (Vaidyanathan, 2013). It is the disciplined implementation of projects using an integrated approach by a competent team satisfying customer requirements in a dynamic competitive environment. Project management activities include establishing a project scope, planning the project, planning clear and adequate communications, evaluating risks at all stages of a project, scheduling project activities, costs, resource requirements and performance measures, monitoring and controlling, and creating project value (Vaidyanathan, 2013). Organizational culture must lend itself to promote those activities and provide opportunities and adequate authority for project managers to effectively accomplish those activities. The selection and involvement of a competent and qualified project manager and a project team is a critical factor for successful project outcomes (Fortune \& White, 2006). Furthermore, the skills and competencies of team members to meet the requirements of a project as well as 
their teamwork skills must be taken into consideration (Ballsteros-Perez et al., 2012). The selection of such a team rests on how organizations foster their project management culture.

\section{Project Resources}

Project resources are available organizational assets, capabilities, processes, and knowledge. Those resources need to be made available to all project managers and team members by the organization. The way organizations manages their knowledge is crucial for their organizational development. The knowledge management needs to allow knowledge dissemination and the culture must inspire knowledge sharing among their employees. Over time, an organization needs to learn and accumulate knowledge, insights, and expertise. Senior management is responsible for building such a knowledge management culture in order for the employees to share their knowledge. Other than knowledge management, a culture needs to exist to train employees in proper use of project management tools. AlliedSignal Corporation, the present day Honeywell, created a corporate culture so that all their employees worked with tools such as Quality Functional Deployment, Cause and Effect Model, Thought Process Map, Brainstorming, and other Continuous Process Improvement techniques in all their projects. In many companies, project team members use certain software to implement projects that are approved by senior management.

\section{Project Environment}

Project environment is another critical dimension of project culture. Project environment brings together diverse groups of people for a short duration and those people are expected to quickly establish a working team. There are a number of stakeholders in each project including contractors, customers, suppliers, and consultants who are expected to work with the team at various periods of time. Whenever a new project is created, it is also important for team members and stakeholders to form new sets of relationships. Moreover, desired norms and values formed among team members is an important condition for project teams and more so among dispersed teams. A uniform and mature project environment defines and forms a fruitful project implementation in organizations.

A project environment should promote the use of various project management components that are essential to realize project success. Such components include clear project definition, good rationale for implementation of project, and how a project is aligned to corporate goals. Successful implementation of projects require a corporate culture that emphasizes the value of sharing common goals over individual pursuits and the value of trust among team members and stakeholders (Stefanou, 1999). A project environment should promote a mature project organizational structure with associated channels of communication, accountabilities, responsibilities, and reporting facilities. A culture of identifying and defining project requirements from stakeholders and establishing those requirements as the project scope ensures project success. A clear set of operational rules and processes ensure an environment that is conducive to making changes that improve work processes. Such an environment also promotes positive work ethic, social norms, and codes of conduct.

Executive management plays a vital role in the selection of value-added projects. An environment that is founded on the achievement of corporate goals regardless of politics, conflicts, and power play is necessary for fair selection of value-added projects. The support and commitment displayed by the executive management towards project management values is viewed as a hallmark of a positive project culture. Young and Jordan (2008) provide empirical evidence that top management support is the most important critical success factor for project success. To build a learning organization, it requires a leader who inspires the vision of the learning organization (Senge, 1990). A learning organization promotes a project culture that infuses learning and supports innovations (Blodgood \& Salisbury, 2001). Senior management through displaying monitoring process must encourage effective long term working relationships between project team members and managers. The commitment to foster such working relationships depends upon trust and open communication (Henderson, 1990). Senior leadership should create a project environment that provides empowerment to project manager and teams with good training facilities as well as good recognition and reward policies.

\section{Project Characteristics}

Projects, in general, are different and are prone to various structures with respect to characteristics such as size, scalability, location, and complexity. For each one of those characteristics, organizations exhibit their cultural differences. Such differences in culture may influence project outcome and success. An empirical investigation has 
shown that project size and complexity displayed some evidence of an association with some of the dimensions of culture (Ankrah et al., 2009).

\section{CONCLUSION AND FUTURE RESEARCH}

Project culture plays a vital role in achieving project success because it sets up an environment for success. Understanding the implications of project culture and the factors that are impacted by it can help organizations to foster positive culture and drive project success. Project managers, team members, and stakeholders need to be cognizant of the project culture framework formulated in this study. This framework will certainly provide them a better insight into cultural consequences when implementing projects. They can consider the impact factors during project initiation stages of project management and take all the necessary steps to mitigate undesirable project outcomes due to project culture. Senior leadership can design, develop, and promote desirable cultural orientations to be successful in their organizational projects.

In this study, we have formulated a framework of project culture. The five project culture dimensions described in this study have a lot of potential for future research. An empirical investigation of the framework is required to check whether the dimensions improve project performance and to test the validity of the conceptual framework. This framework can be used by practitioners to understand how those dimensions impact project success in their organizations. The project culture dimensions may also impact each other and such impacts can be validated using empirical research. There may be attributes of projects that may act independently with respect to project culture. Another interesting research is to understand how project culture can be used to satisfy customer requirements. The proposed research will enrich our knowledge of project cultures and enhance organizational policies towards building well-established project and project management practices.

\section{REFERENCES}

Ankrah, N. A., Proverbs, D. \& Debrah, Y. (2009). Factors influencing the culture of a construction project organization: an empirical investigation. Engineering, Construction and Architectural Management, 16(1), 26-47.

Ballsteros-Perez, P., Gonzales-Cruz, M.C., \& Diego, M.F. (2012). Human resource allocation management in multiple projects using sociometric techniques. International Journal of Project Management, 30(8), 901913.

Blodgood, J.M., \& Salisbury, W.D. (2001). Understanding the influence of organizational change strategies on information technology and knowledge management strategies. Decision Support Systems, 31, 55-69.

Cameron, K.S. \& Quinn, R.E. (1999). Diagnosing and changing organizational culture. Hoboken, NJ: Addison Wesley.

Chell, E. (1994). Making the right decision, organizational culture, vision, and planning. International Small Business Journal, 12(2), 90-94.

Christenson, D., \& Walker, D.H.T. (2004). Understanding the role of "vision" in project success. Engineering Management Review, 32(4), 57-73.

Doolen, T.L., Hacker, M.E., \& Van Aken, E.M. (2003). Impact of organizational context on work team effectiveness: a study of production team, IEEE Transactions on Engineering Management, 50(3), 285296.

Douthit, J.D., \& Stevens, D.E. (2015). The robustness of honesty effects on budget proposals when the superior has rejection authority. The Accounting Review, 90(2), 467-493. 
Dube, L. \& Robey, D. (1999). Software stories: three cultural perspectives on the organizational practices of software development. Accounting Management and Information Technologies, 9, 223-259.

Eskerod, P \& Skriver, P. (2007). Organizational culture restraining in-house knowledge transfer between project managers- A case study. Project Management Journal, 38(1), 110-122.

Fortune, J., \& White, D. (2006). Framing of project critical success factors by a systems model. International Journal of Project Management, 24(1), 53-65.

Müller, R., \& Turner, R. (2007). The influence of project managers on project success criteria and project success by type of project. European Management Journal, 25(4), 298-309.

Nair, G., Suma, V., \& Shashi Kumar. N.R. (2012). Impact analysis of allocation of resources by project manager on success of software projects. Proceedings of the International Conference on Data Mining and Computer Engineering, December 21-22, 2012, Bangkok, Thailand.

PMBOK (2008). A guide to project management body of knowledge (4th edition). Newton Square, PA: Project Management Institute.

Schein, E.H. (2004). Organizational culture and leadership (3rd edition). Hoboken, NJ: John Wiley \& Sons, Inc.

Henderson, J.C. (1990). Plugging into strategic partnerships: the critical IS connection. Sloan Management Review, $31(3), 7-18$.

Schneider, B., Brief, A.P., \& Guzzo, R.A. (1996). Creating a climate and culture for sustainable organizational change. Organizational Dynamics, 24, 7-19.

Schneider, W.E. (1994). The reengineering alternative: a plan for making your current culture work. Burr Ridge, Illinois: Irwin.

Senge, P.M. (1990). The fifth discipline: the art \& practice of the learning organization. New York, NY: Currency Doubleday.

Shore, B. (2008). Systematic biases and culture in project failures. Project Management Journal, 39(4), 5-16.

Silvester, J., Anderson, N., \& Patterson, F. (1999). Organizational culture change: an intergroup attributional analysis. Journal of Occupational and Organizational Psychology, 72(1), 1-23.

Stefanou, C. (1999). Supply chain management and organizational key factors for successful implementation of enterprise resource planning systems. Proceeding of the Americas Conference on Information Systems, August 13-15, Milwaukee, WI.

Thomas, J., \& Mullaly, M. (2009). Guest editorial: explorations of value: perspective on the value of Project Management. Project Management Journal, 40(1), 2-4.

Vaidyanathan, G. (2013). Project management: process, technology, and practice. Upper Saddle River, NJ: Pearson Prentice-Hall.

Wideman, R.M. (1990). Managing the project environment. In H. Reschke \& H. Schelle (Ed.), Dimensions of project management, Berlin, Germany: Springer-Verlag.

Williams, T. (2007). Post-project reviews to gain effective lessons learned. Newtown Square, PA: Project Management Institute. 
Xiaoli, Y. \& Hongping, C. (2011). Establishment and realization of project culture during the construction project management in China. IEEE 2011 International Conference on Management and Service Science (MASS), August 12-14, Wuhan, China.

Young, R., \& Jordan, E. (2008). Top management support: mantra or necessity? International Journal of Project Management, 26(7), 713-725.

Zuo, J. \& Zillante, G. (2006). Project culture: the x factor for achieving optimum performance in construction projects? Construction Information Quarterly, 8(4), 173-177. 